\section{Tissue Factor}

T. Stief

Institut für Laboratoriumsmedizin und Pathobiochemie, Marburg, Deutschland

Synonym(e) Gewebsfaktor; Thromboplastin; Gerinnungsfaktor III; CD 142; TF

Englischer Begriff tissue factor; TF

Definition Tissue Factor (TF) ist Kofaktor für F7/F7a. Wichtigstes Substrat des TF-F7a-Komplexes (extrinsische Tenase) ist F10.

Beschreibung TF ist ein ca. $45 \mathrm{kDa}$ großes Typ-I-integrales Membranprotein, dessen extrazellulärer Teil aus zwei - Fibronectin-Typ-III-Domänen besteht. TF besitzt eine nur aus 23 Aminosäuren bestehende zytoplasmatische Domäne, deren Funktion nicht bekannt ist, jedoch wohl keine prokoagulatorische Funktion besitzt. Unter normalen Bedingungen wird TF nicht auf Zellen gefunden, die in einem direkten Kontakt mit der Zirkulation sind. Erst eine Schädigung des Zellverbandes führt zu einer Exposition von TF auf der Zelloberfläche. Der TF wird dort sehr hoch exprimiert gefunden, wo eine Blutung fatale Folgen hätte, z. B. in Gehirn, Nierenglomeruli, Plazenta. TF ist allosterischer Aktivator von F7/F7a. Inhibiert werden die TF-7a-Komplexe durch den „tissue factor pathway inhibitor“ (TFPI). Tissue Factor wird im Thromboplastinreagenz für den Quick-Test $(\triangleright$ Thromboplastinzeit) verwendet. Thromboplastine können aus Hirngewebe, Lunge oder Plazenta verschiedener Spezies gewonnen oder rekombinant in eukaryontischen oder prokaryontischen Expressionssystemen hergestellt werden. Tissue Factor ist ein interessanter Biomarker für extrinsische Gerinnungsaktivierung wie z. B. bei Sepsis. Intensivpflichtige Patienten mit schwerer Sepsis haben ca. 4-fach erhöhte Plasmakonzentrationen an TF.

Normbereich $140 \pm 42 \mathrm{pg} / \mathrm{mL}$; Patienten mit schwerer Sepsis haben $568 \pm 225 \mathrm{pg} / \mathrm{mL}$.

Messtechnik Enzymimmunoassay. EDTA-Plasma sollte mit $1,25 \mathrm{M}$ Arginin, pH 8,7 stabilisiert sein. In der CaptureAntibody-Antigen-Reaktion sollten 400-600 mM Arginin anwesend sein, um eine unspezifische Zerstörung des Antigens (hier: TF) zu verhindern.

\section{Literatur}

Morrissey JH (2004) Tissue factor: a key molecule in hemostatic and nonhemostatic systems. Int J Hematol 79:103-108

Stief TW, Ijagha O, Weiste B, Herzum I, Renz H, Max M (2007) Analysis of hemostasis alterations in sepsis. Blood Coagul Fibrinolysis 18:179-186

Stief TW, Ulbricht K, Max M (2010) ICAM-1, tissue factor, protein C, and AT3 dynamic in severe sepsis. Hemost Lab 3:239-249 